\title{
Dyskinesia in Multiple System Atrophy and Progressive Supranuclear Palsy
}

Wolfgang H. Jost ${ }^{1}$, Paul Lingor ${ }^{2}$, Lars Tönges ${ }^{3,4}$, Johannes Schwarz ${ }^{5}$, Carsten Buhmann $^{6}$, Jan Kassubek ${ }^{7}$, Anette Schrag ${ }^{8}$

${ }^{1}$ Parkinson-Klinik Ortenau, Wolfach, Germany

${ }^{2}$ Klinik für Neurologie, Klinikum rechts der Isar der TU München, München, Germany

${ }^{3}$ Department of Neurology, St. Josef-Hospital, Ruhr-University Bochum, Bochum, Germany

${ }^{4}$ Neurodegeneration Research, Protein Research Unit Ruhr (PURE), Ruhr University Bochum, Bochum, Germany

${ }^{4}$ Dept. of Neurology, Klinik Haag i. OB

${ }^{6}$ Department of Neurology, University Clinic Eppendorf, Hamburg, Germany

${ }^{7}$ Department of Neurology, University of Ulm, Germany

${ }^{8} \mathrm{UCL}$ Institute of Neurology, London, UK

Corresponding author:

Prof. Dr. Wolfgang Jost

Parkinson-Klinik Ortenau

Kreuzbergstr. 12

77709 Wolfach, Germany

Tel. +49-7834-971212; Fax: +49-7834-971340

Email: W.Jost@parkinson-klinik.de 
Abstract:

In the differential diagnosis of Parkinson syndromes, the response to L-Dopa is an essential criterion for the diagnosis of idiopathic Parkinson's disease (IPD), and the presence of L-Dopa-induced dyskinesia (LID) is considered a supportive criterion. This implies that in the presence of LID an atypical Parkinson-syndrome (APS) is unlikely. However, dyskinesia, and in particular LID, can also be present in APS such as MSA and PSP, although less frequently, and with varying clinical appearance. We conclude that whilst presence of dyskinesia provides support for a diagnosis of IPD, they do not allow reliable differentiation from APS.

Key-words: Dyskinesia, Parkinson's disease, Multiple System Atrophy, Progressive Supranuclear Palsy 


\section{$\underline{\text { Introduction }}$}

An important motor complication in the course of drug therapy of neurodegenerative parkinsonism is the occurrence of the so-called levodopa-induced dyskinesia (LID). LID are usually classified as peak-dose dyskinesia, wearing-off or off-period dyskinesia, and biphasic dyskinesia. In addition, dystonia in the absence of treatment may occur The exact causes of dyskinesia are not yet clarified. An essential prerequisite for the occurrence of LID is the response to levodopa. The main risk factor is long duration of treatment, but occasionally LID may be observed even after only a few days or months of treatment (Cilia 2014 Brain). In addition, young age of onset and high daily doses are considered major risk factors (Fahn 1999, Olanow 2013, Stocchi 2010). LID, or severe levodopa-induced chorea, are considered to be a supportive prospective positive criteria for PD (Gibb and Lees 1988) and their presence is often regarded as making an atypical Parkinson syndrome (APS) unlikely.

The topic of this workshop was to compile and discuss the evidence whether dyskinesia also occur in Multiple System Atrophy (MSA) and Progressive Supranuclear Palsy (PSP), whether these differ from LID in PD, whether a response to levodopa is a prerequisite for the occurrence of the LID. We discussed current clinical practice and then re-evaluated the existing literature.

\section{Pathophysiology of levodopa-induced dyskinesia (LID)}

Dyskinesia or abnormal involuntary movements can be side effects of various medications, with levodopa (or dopamine agonists) most commonly being associated with dyskinesia in patients with Parkinson's disease (PD) or atypical Parkinson syndrome (APS). However, their pathophysiology is not well understood. Possible additional causes that have been considered are (i) non-physiological (pulsatile) dopamine replacement therapy, (ii) progressive degeneration of dopaminergic neurons, (iii) levodopa uptake and innervation of striatal neurons via nondopaminergic (serotonergic) neurons, (iv) supersensitivity of dopamine D2 (-like) receptors (DRD2), (v) levodopa-induced synaptic plasticity of medium spiny GABAergic striatal projection neurons, and (vi) alterations of neuronal networks. Thus, LID in patients with PD are often attributed to pulsatile dopaminergic 
stimulation together with the short half-life of levodopa and also the abnormal release of dopamine from serotonergic neurons (Nutt 2007, Politis 2014). Levodopa is therefore considered necessary but insufficient to generate LID since LID requires combinations of pulsatile delivery (short half-life), presynaptic nigrostriatal degeneration, metabolism of excess levodopa in serotonergic neurons, a relatively preserved post-synaptic nigrostriatal system and downstream changes of postsynaptic signaling molecules (Espay 2018).

The importance of pulsatile stimulation is supported by the fact that peak-dose dyskinesia increases in a dose-dependent manner with orally administered levodopa, whereas continuous levodopa infusion (levodopa carbidopa intestinal gel, LCIG) can reduce dyskinesia despite higher daily doses of levodopa (Olanow 2014). LID gradually emerges with oral therapy over time, i.e. the threshold for dyskinesia (which typically is initially higher than the threshold for a motor benefit) is lowered corresponding to a shift of the dose-response curve to the left, consistent with sensitization. However, motor fluctuations are complex with evidence for both sensitization and tolerance, depending upon what aspects of the motor response are examined (Mouradian 1988). Given that extracellular striatal dopamine concentrations are not constant in the normal brain, the pattern of variations in striatal dopamine concentrations in the conventionally levodopa-treated parkinsonian brain will not mimic the normal pattern (Nutt 2007). Uptake of levodopa into serotonergic neurons was initially suggested when an increase of LID was noticed after transplantation of fetal mesencephalic tissue. Subsequently, imaging studies confirmed that dopamine release from serotonergic neurons and its modulation via serotonin receptor activation (5HT1A) relate to LID (Politis 2014).

Changes within postsynaptic medium spiny neurons also appear to contribute to the pathophysiology. Dyskinesia can be caused not only by dopamine and dopamine agonists but also by dopamine receptor antagonists. Neuroleptic-induced dyskinesia and LID are similar in their clinical phenomenology, epidemiology, risk factors and pathophysiological mechanisms (Rascol and Fabre 2001; Sachdev 2000, Sawa and Snyder, 2002). Typical neuroleptics are selective antagonists at dopamine D2 (-like) receptors (DRD2), so that an increase in signaling through DRD2 is assumed to be relevant. Chronic inhibition of dopamine signaling along the nigrostriatal dopamine pathway can produce a compensatory upregulation in the striatal DRD2 level and increased coupling to the linked Ga protein (Cai et al., 2002), resulting in the 
hypothesized increase in DRD2 signaling (Geurts 1999, Ginovart 1999). More specifically, Sanci and colleagues (Sanci 2002) and Drucker and colleagues (Drucker 1994) showed that neuroleptic treatment produces supersensitivity of striatal D2 but not D1 dopamine receptors. Loss of dopaminergic terminals as observed in PD also results in a compensatory DRD2 upregulation in early diseased patients (Antonini et al., 1994). On the other hand, levodopa treatment usually causes LID in patients with PD only following several years of disease (Marsden 1994), when DRD2 binding has returned to normal or subnormal values (Antonini 1997). Thus, additional changes downstream of DRD2 activation seem to be required to produce abnormal involuntary movements (AIMs).

Thus, neuroleptic-induced and also levodopa-induced dyskinesia have been linked to non-physiological DRD2 stimulation, resulting in altered expression of glutamate receptors and firing patterns of downstream nuclei within the basal ganglia loop. Temporal patterns of electrical activity are disrupted within the globus pallidus and the subthalamic nucleus in MPTP/levodopa treated monkeys (Vitek and Giroux, 2000). Molecular mechanisms have mainly been studied in rats. There is evidence for alterations of NMDA receptors: increased expression, hyperphosphorylation and abnormal trafficking (Dunah et al., 2000). These findings motivated experiments showing that blockade of NMDA receptors can reduce abnormal levodopa-induced behavior in monkeys (Blanchet 1998, Papa and Chase 1996). Since low-affinity glutamate receptor antagonists have been used to treat PD, these preclinical data were transferred to clinical studies: amantadine significantly reduced levodopainduced AIM in patients with PD (Verhagen Metman 1998). At present, it is not clear how GPCRs (G-protein coupled receptor) such as dopamine receptors couple to ligand-gated ion channels such as NMDA or AMPA receptors. One may speculate that modulation of the activity of second and third messenger molecules such as kinases, etc. are involved. On the other hand, Niznik and coworkers described an intriguing model for direct blockade of NMDA receptors via the intracellular C-terminal tail of DRD1 following activation (Lee 2002). In addition, the coupling of dopamine receptors to G-proteins seems more complex since individual receptors can couple to different G proteins (Sidhu and Niznik 2000). However it seems likely that modulations of glutamate receptor expression represent molecular changes that occur several steps downstream of non-physiological DRD2 stimulation. 
Beyond the similarities of dyskinesia induced by levodopa and neuroleptics converging on DRD2, overactivation of dopamine D1 (-like) receptors (DRD1) is associated with multiple molecular changes within striatal medium spiny neurons including activation of the mitogen and stress-activated kinase- 1 which is regarded as a major factor in the regulation of synaptic plasticity and transcriptional activity (Calabresi 2010). Current concepts include abnormalities in non-dopaminergic neurotransmitters, i.e. the cholinergic, opioid, histaminic, adrenergic, glutamatergic, and cannabinoid systems (Espay 2018).

Furthermore changes in synaptic signaling leads to changes in neuronal networks. Data from animals and humans suggest that alterations in firing patterns in the globus pallidus pars interna and in the subthalamic nucleus secondary to overstimulation of dopamine receptors in the dysfunctional striatum are associated with LID (Espay 2018). Changes in the coherence between (motor) cortical structures and subcortical modulators seem to be a major factor in humans, including a reduction of power in the beta-band local field potential activity and narrowband hypersynchronous gamma oscillations in the motor cortex and the subthalamic nucleus with strong phase coherence between the two (perturbation in oscillatory dynamics) (Swann 2016), although the role of plastic alterations at the cortical level is still not well defined in this context, either in PD or in other neurodegenerative parkinsonism.

\section{Neuropathological evidence}

Dyskinesia is very rare in patients with PSP, and only few single pathological reports of patients with PSP and dyskinesia have been published. Except for a patient with additional Lewy bodies (overlap syndrome), no clear distinguishing pathological features have been described in these (Birdi 2002). In MSA, on the other hand, a substantial proportion of patients can experience dyskinesia, especially during the early stages of the disease. The underlying pathology for dyskinesia, which may occur even in untreated MSA, is thought to be related to putaminal degeneration, or degeneration of interconnections between the striatum and brainstem or cerebellum (Boesch et al, 2002). However, in a series of pathologically confirmed patients with MSA who underwent DBS surgery, of whom most experienced peak-dose dyskinesia, a typical distribution of pathological changes was seen in the striatum at postmortem (Meissner 2016). In the recent review of young-onset cases of MSA 
(Batla et al, 2018), 56\% had dyskinesia. Amongst those with pathologically confirmed young onset MSA $43 \%$ also had dyskinesia (compared to $94 \%$ in young-onset Parkinson's disease) and 29\% had orofacial dyskinesia which was not recorded in any of the young-onset PD cases. Those with pathological confirmation were also found more likely to have the minimal-change pathological variant than those with late onset of the disease, with neuronal loss largely localized to the substantia nigra and the locus coeruleus ( 2 cases), while a further six had neuronal loss particularly in the striatonigral and olivopontocerebellar structures (three cases) and in the olivopontocerebellar structures (three cases). In an additional informative case report of a patient with pathologically confirmed young-onset MSA treated with DBS for severe dyskinesia there was also minimal-change pathological confirmation of MSA with significant cell loss restricted to the substantia nigra. Whilst there are therefore currently unequivocal data on the pathological substrate of the occurrence of dyskinesia in MSA, dyskinesia occur in the context of relatively preserved postsynaptic striatal neurons (Boesch 2002, Huang et al, 2005).

\section{Clinical evidence for the presence of dyskinesia in MSA}

Over the course of multiple system atrophy (MSA), various neuronal pathways are affected by a neurodegeneration. This results in a multifaceted clinical presentation with parkinsonism, cerebellar ataxia, and autonomic failure in variable combinations (Wenning et al., 2013; Low et al., 2015; Krismer and Wenning, 2017). Two major motor presentations can be distinguished. MSA parkinsonism (MSA-P) is the MSA form that predominates in Western countries and is characterized by a rapidly progressive akinetic-rigid syndrome with a poor response to treatment with levodopa due to striatal neurodegeneration (Krismer and Wenning, 2017). Disease progression is faster than in PD and postural instability and falls emerge already within the first three years of disease onset (Williams and Litvan, 2013). The cerebellar type (MSAC) shows prominent cerebellar symptoms including gait and limb ataxia, scanning dysarthria as well as oculomotor disturbances such as gaze-evoked nystagmus and hypometric saccades (Krismer and Wenning, 2017). By definition, all MSA patients exhibit pronounced autonomic dysfunction, affecting urogenital and cardiovascular autonomic domains (Gilman et al., 2008). Human neuropathological examinations have revealed that the primarily affected cell populations are oligodendrocytes which 
harbor alpha-synuclein immunopositive inclusions (Trojanowski et al., 2007). In addition, prominent neuronal loss and astrogliosis are present (Koga and Dickson, 2018). It is assumed that there is a propagation mechanism for alpha-synuclein that is responsible for the disease spread in MSA resulting in neurodegeneration in many different brain regions (Krismer and Wenning 2017, Wenning 2018).

Dyskinesia in MSA is observed almost exclusively in the MSA-P subtype where parkinsonism is often treated with dopaminergic therapies but classically responds poorly. However, levodopa therapy causes complications such as motor fluctuations in MSA as well. These dyskinesia typically have a craniocervical predominance and are mostly dystonic (Boesch 2002). However, these are not exclusive since peak dose dyskinesia occur and may be associated with slower progression (Berciano 2002, O'Sullivan S 2008). Williams and Litvan locate MSA dyskinesia primarily to the axial segment (Williams and Litvan 2013), whereas Espay and coworkers locatetypical MSA dyskinesia more to the feet (Espay 2018).

In a prospective European MSA cohort study, 141 patients were closely followed of whom $62 \%$ were classified as MSA-P and $38 \%$ as having MSA-C. A beneficial response to levodopa was reported in $43 \%$ of MSA-P and in $13 \%$ of MSA-C patients, lasting for a mean duration of three to four years. Of all these patients a minority encountered motor complications including wearing-off fluctuations in $23 \%$, offdystonia in $20 \%$, on-off motor fluctuations in $14 \%$, but peak-dose dyskinesia were reported only in $11 \%$ of levodopa-responsive patients (Wenning 2013). Similar observations were found in the corresponding prospective US MSA cohort study (Low 2015).

A recent analysis of young-onset MSA patients with an age of less than 40 years included 22 patients (20 MSA-P and 2 MSA-C type) (Batla 2018). The mean age at MSA onset was 36.7 years. In comparison to young-onset PD, LID were less common in MSA patients but orofacial dystonia in response to levodopa was only seen in young-onset MSA but not in young-onset PD. However, if the young-onset MSA patients were compared to late-onset MSA patients from the above mentioned European MSA cohort, dystonia, levodopa responsiveness but also levodopainduced dyskinesia, were more common in young patients. In detail, $83 \%$ of youngonset MSA subjects had an initial response to levodopa and $44 \%$ developed limb 
and/or orofacial dyskinesia (Batla 2018). A rather high prevalence of dyskinesia was again found in four out of five late-onset cases from a retrospective study in neuropathologically confirmed MSA-P patients which had been initially diagnosed as PD and had received deep brain stimulation (Meissner 2016).

These data suggest that the occurrence of dyskinesia is not a reliable distinguishing feature of PD and MSA, as dyskinesia can occur to a considerable degree as levodopa-induced motor complications in MSA patients, especially in the MSA-P type and in early-onset MSA patients. However, orofacial distribution and off-period and wearing-off dystonia are more common in MSA. In particular, the occurrence of dyskinesia resp. dystonia of the oromandibular region and of the platysma suggest MSA in the differential diagnosis.

\section{Clinical evidence for the presence of dyskinesia in PSP}

Progressive supranuclear palsy (PSP) is pathologically characterized by cerebral intracellular tau aggregation which leads to neurodegeneration (Frosch, 2017). The clinical spectrum of neuropathologically defined PSP is broad and can show an overlap with autopsy-confirmed MSA, PD, and frontotemporal dementia (FTD) (Respondek and Höglinger, 2016), which has led to novel criteria for the clinical diagnosis of PSP (Höglinger 2017). As shown in PD for alpha-synuclein, tau is also thought to spread transneuronally in a prion-like manner (Lim and Yue 2015, Mudher 2017) and it is suggested that different PSP phenotypes might be related to differential seeding and spreading properties of distinct tau strains (Narasimhan 2017).

Clinically, poor response to dopaminergic drugs is one diagnostic criterion suggested to be useful in distinguishing APS from PD (Suchowersky 2006). Thus "poor or absent response of parkinsonism" to LD is supportive of PSP diagnosis while marked and prolonged LD benefit has been included as a mandatory exclusion criterion for PSP (Litvan 2003).

Dyskinesia in PSP patients is "rare" (Litvan 1996, Lang 2005), and LID is typically not observed in PSP (Respondek and Hoglinger 2016), but there is lack of systematic study data. LID in PD is linked to responsiveness to levodopa and based on a relatively preserved post-synaptic nigrostriatal system (Espay 2018). In contrast to 
PD, PSP patients with the most common Richardson phenotype (PSP-RS) usually do not respond to levodopa, and the post-synaptic dopaminergic system is also affected in these patients (Williams and Litvan 2013). In accordance, Lang suggested that in PSP patients, "the usual absence of dyskinesias as a side effect, even with high doses of levodopa, probably relates to the prominent pathological involvement of the internal segment of the globus pallidus, essentially resulting in an 'autopallidotomy"" (Lang, 2005).

However, patients with PSP-Parkinson (PSP-P) phenotype who represent about 20$32 \%$ of PSP patients, often show a moderate initial response to LD and because they frequently present with concomitant asymmetric parkinsonism and tremor, they are clinically often indistinguishable from PD in the first years of disease (Williams 2005, Levin 2016).

Constantinescu et al. reviewed eight publications with in total about 228 medicated PSP patients and reported at least some LD response in $26 \%$ to $38 \%$ of these patients within the first year of illness (Constantinescu et al., 2007). Considering the studies reviewed (Nieforth and Golbe 1993, Williams 2005, Kompoliti 1998) and a recent investigation (Vasta 2017), the degree of LD response varies from minimal/very low to marked/good (Kompoliti 1998, Nieforth and Golbe 1993, Vasta 2017, Williams 2005). However, included PSP patients have not been classified into clinical subtypes. Dyskinesia have been reported in about ten of the 228 PSP patients from the review (Constantinescu 2007), suggesting a prevalence rate of about $4.4 \%$, but PSP was proven by autopsy in only seven of these ten patients. When separating the 228 PSP patients into two groups, one with 95 patients in the largest study by Williams and coworkers (Williams 2005) and one with 133 patients in the remaining seven studies, the prevalences of dyskinesia match quite well with $4.0 \%$ in the study by Williams et al. and about $4.5 \%$ in the remaining 7 reports. There is a further single-case report describing LID in an autopsy-proven case of PSP (Kim 2002). Studies in PSP patients aiming to systematically report or investigate dyskinesa are lacking. Like in PD, dyskinesia found in PSP patients usually was based on at least some LD-responsiveness and were related to LD therapy. However, "some (PSP) patients with dyskinesia may obtain little or no clinical benefit otherwise" (Lang 2005). Birdi et al. even described blepharospasm and intermittently occurring facial dyskinesia in two drug-naïve PSP patients. Facial dyskinesia 
presented as tonic contraction or grimacing of one or the other side and they worsened on dopaminergic treatment (Birdi 2002).

Dyskinesia in PSP patients has been described in most cases only to be facial and, when more detail was given, as occurring as LID with jaw clenching, retraction of the mouth angles or as intermittent unilateral tonic facial muscle contractions or blepharospasm (Birdi 2002). However, LID of the limbs have been reported in two cases, presenting as choreatic dyskinesia in combination with blepharospasm in one case (Birdi 2002), in the other case as LD-dose dependent occurring in one leg with semirhythmic flexion-extension of the left knee and internal rotation as well as adduction of the hip joint (Kim 2002). Noteworthy, one patient with limb dyskinesia had combined Lewy body and PSP pathology (Birdi 2002).

Further clinic-pathological studies should investigate whether dyskinesia in PSP is linked to certain clinical or pathological phenotypes, such as overlap syndromes of tau- and alpha-synucleinopathy or with underlying genetic overlap of PSP and PD with MAPT H1-specific polymorphisms or genetic forms with rare variants in the LRRK2 gene as found in autopsy-proven PSP, respectively (Respondek 2018).

\section{Discussion}

In summary, there is ample clinical and pathological evidence for the occurrence of LID in parkinsonian disorders other than PD, e.g. MSA or PSP. However, several points need to be considered:

1) Diagnostic certainty: the rate of misdiagnosis of patients at lifetime is known to be high. Thus, patients with PD may be diagnosed with PSP or MSA and LID are actually observed as part of misdiagnosed PD.

2) Phenotypical heterogeneity: dyskinesia in MSA and PSP patients may differ from the ones observed in PD and the terminology used may be ambiguous (including distribution, timing and differentiation of treatment-induced vs spontaneous dyskinesia).

3) Pathological heterogeneity: disease progression on the histological level is not uniform in all PD patients (Rietdijk 2017), and not all patients with PD develop dyskinesia. Heterogeneity of disease spread and thus heterogeneity of affected brain regions are also likely to exist in MSA and PSP, opening the possibility of relative post-synaptic preservation, which then can predispose to LID, similar to PD. 
4) Underdosage: LID is evoked by pulsatile dopaminergic stimulation and in most cases requires high doses of levodopa. Many patients with MSA or PSP do not receive high doses of levodopa, because the drug has been discontinued due to insufficient clinical effects or unwanted side-effects. In contrast, almost all patients with PD receive dopaminergic medication and at some point progress to higher levodopa doses, thus increasing the likelihood for LID. Therefore, although some patients with APS could be more prone to develop LID, they may fail to develop LID due to limited dopaminergic stimulation.

There are ongoing efforts to improve the subtyping of parkinsonian syndromes using a combination of clinical features, MRI or PET imaging and molecular biomarkers (e.g. Fereshtehnejad 2017, Zhang 2019). These analyses may also help to identify subgroups within disease entities, such as MSA or PSP, that are predisposed to the development of dyskinesia and yield further explanation on why some patients are more prone than others to develop dyskinesia in the course of their disease.

\section{Conclusion}

Based on the evidence available, we thus suggest:

Dyskinesia, and especially LID can also occur in atypical parkinsonian syndromes, such as MSA or PSP, albeit less frequently than in PD.

- The clinical picture of dyskinesia in MSA and PSP may differ from dyskinesia in PD (e.g. more frequent oromandibular or axial distribution), but the clinical heterogeneity does not permit using the phenomenology as a reliable factor differentiating between disease entities.

There is currently a lack of adequate epidemiological data on dyskinesia in APS as well as clinical classifications.

Therefore, the presence or absence of dyskinesia does not reliably differentiate between IPS and APS

\section{References}

Antonini A, Schwarz J, Oertel WH, Beer HF, Madeja UD, Leenders KL (1994) [11C]raclopride and positron emission tomography in previously untreated patients 
with Parkinson's disease: Influence of L-dopa and lisuride therapy on striatal dopamine D2-receptors. Neurology 44: 1325-1329

Antonini A, Schwarz J, Oertel WH, Pogarell O, Leenders KL (1997) Long-term changes of striatal dopamine D2 receptors in patients with Parkinson's disease: a study with positron emission tomography and [11C]raclopride. Mov Disord 12: 33-8

Batla A, De Pablo-Fernandez E, Erro R, Reich M, Calandra-Buonaura G, Barbosa P, Balint B, Ling H, Islam S, Cortelli P, Volkmann J, Quinn N, Holton JL, Warner TT, Bhatia KP (2018) Young-onset multiple system atrophy: Clinical and pathological features. Mov Disord 33: 1099-1107

Berciano J, Valldeoriola F, Ferrer I, Rumià J, Pascual J, Marín C, Rey MJ, Tolosa E (2002) Presynaptic parkinsonism in multiple system atrophy mimicking Parkinson's disease: a clinicopathological case study. Mov Disord 17: 812-816

Birdi S, Rajput AH, Fenton M, Donat JR, Rozdilsky B, Robinson C, Macaulay R, George D (2002) Progressive supranuclear palsy diagnosis and confounding features: report on 16 autopsied cases. Mov Disord 17: 1255-1264

Blanchet PJ, Konitsiotis S, Chase TN (1998) Amantadine reduces levodopa-induced dyskinesias in parkinsonian monkeys. Mov Disord 13: 798-802

Boesch S. Wenning GK, Ransmayr G, Poewe W (2002) Dystonia in multiple system atrophy. J Neurol Neurosurg Psych 72: 300-303

Cai DF, Chen XQ, Gao Y (2002) [Effect of bushen yanggan recipe on nigrostriatal function in parkinsonian model rats after long-term levodopa treatment]. Zhongguo Zhong Xi Yi Jie He Za Zhi22: 43-46

Calabresi P, Di Filippo M, Ghiglieri V, Tambasco N, Picconi B (2010) Levodopainduced dyskinesias in patients with Parkinson's disease: filling the bench-to-bedside gap. Lancet Neurol 9: 1106-1117

Cilia R, Akpalu A, Sarfo FS, Cham M, Amboni M, Cereda E, Fabbri M, Adjei P, Akassi J, Bonetti A, Pezzoli G (2014) The modern pre-levodopa era of Parkinson's disease: insights into motor complications from sub-Saharan Africa. Brain 137: 2731-2742 Constantinescu R, Richard I, Kurlan R (2007) Levodopa responsiveness in disorders with parkinsonism: a review of the literature. Mov Disord 22: 2141-2148

Drucker GE, Ritzmann RF, Wichlinski LJ, Engh K, Gordon JH, Fields JZ (1994) Prevention and reversal of dopamine receptor supersensitivity by cyclo(leucyl-glycyl) (CLG): biphasic dose-response curves. Pharmacol Biochem Behav 47: 141-145 
Dunah AW, Wang Y, Yasuda RP, Kameyama K, Huganir RL, Wolfe BB, Standaert DG (2000) Alterations in subunit expression, composition, and phosphorylation of striatal $\mathrm{N}$-methyl-D-aspartate glutamate receptors in a rat 6-hydroxydopamine model of Parkinson's disease. Mol Pharmacol 57: 342-352

Espay AJ, Morgante F, Merola A, Fasano A, Marsili L, Fox SH, Bezard E, Picconi B, Calabresi P, Lang AE (2018) Levodopa-induced dyskinesia in Parkinson disease: current and evolving concepts. Ann Neurol 84: 797-811

Fabbrini G, Brotchie JM, Grandas F, Nomoto M, Goetz CG (2007) Levodopa-induced dyskinesias. Mov Disord. 22:1379-1389

Fahn S (1999) Parkinson disease, the effect of levodopa, and the ELLDOPA trial. Earlier vs Later L-DOPA. Arch Neurol 56: 529-535

Fereshtehnejad SM, Zeighami Y, Dagher A, Postuma RB (2017) Clinical criteria for subtyping Parkinson's disease: biomarkers and longitudinal progression. Brain 140: 1959-1976

Frosch MP (2017) Tau aggregates: where, when, why and what consequences? Neuropathol Appl Neurobiol 43: 371-372

Geurts M, Hermans E, Maloteaux JM (1999) Enhanced striatal dopamine D(2) receptor-induced [35S]GTPgammaS binding after haloperidol treatment. Eur J Pharmacol 382: 119-127

Gibb WR, Lees AJ (1988) A comparison of clinical and pathological features of youngand old-onset Parkinson's disease. Neurology 38: 1402-1406

Gilman S, Wenning GK, Low PA, Brooks DJ, Mathias CJ, Trojanowski JQ, Wood NW, Colosimo C, Durr A, Fowler CJ, Kaufmann H, Klockgether T, Lees A, Poewe W, Quinn N, Revesz T, Robertson D, Sandroni P, Seppi K, Vidailhet M (2008) Second consensus statement on the diagnosis of multiple system atrophy. Neurology 71: 670-676

Ginovart N, Farde L, Halldin C, Swahn CG (1999) Changes in striatal D2-receptor density following chronic treatment with amphetamine as assessed with PET in nonhuman primates. Synapse 31: 154-162

Höglinger GU, Respondek G, Stamelou M, Kurz C, Josephs KA, Lang AE, Mollenhauer B, Muller U, Nilsson C, Whitwell JL, Arzberger T, Englund E, Gelpi E, Giese A, Irwin DJ, Meissner WG, Pantelyat A, Rajput A, van Swieten JC, Troakes C, Antonini A, Bhatia KP, Bordelon Y, Compta Y, Corvol JC, Colosimo C, Dickson DW, Dodel R, Ferguson L, Grossman M, Kassubek J, Krismer F, Levin J, Lorenzl S, Morris HR, Nestor P, Oertel WH, Poewe W, Rabinovici G, Rowe JB, Schellenberg GD, Seppi K, 
van Eimeren T, Wenning GK, Boxer AL, Golbe LI, Litvan I (2017) Clinical diagnosis of progressive supranuclear palsy: The movement disorder society criteria. Mov Disord 32: 853-864

Huang Y, Garrick R, Cook R, O'Sullivan D, Morris J, Halliday GM (2005) Pallidal stimulation reduces treatment-induced dyskinesias in "minimal-change" multiple system atrophy. Mov Disord 20: 1042-1047

Kim JM, Lee KH, Choi YL, Choe GY, Jeon BS (2002) Levodopa-induced dyskinesia in an autopsy-proven case of progressive supranuclear palsy. Mov Disord 17:1089-1090 Koga S, Dickson DW (2018) Recent advances in neuropathology, biomarkers and therapeutic approach of multiple system atrophy. J Neurol Neurosurg Psychiatry 89: 175-184

Kompoliti K, Goetz CG, Litvan I, Jellinger K, Verny M (1998) Pharmacological therapy in progressive supranuclear palsy. Arch Neurol 55: 1099-1102

Krismer F, Wenning GK (2017) Multiple system atrophy: insights into a rare and debilitating movement disorder. Nat Rev Neurol 13: 232-243

Lang AE (2005) Treatment of progressive supranuclear palsy and corticobasal degeneration. Mov Disord 20 Suppl 12: S83-S91

Lee FJ, Xue S, Pei L, Vukusic B, Chéry N, Wang Y, Wang YT, Niznik HB, Yu XM, Liu $F$ (2002) Dual regulation of NMDA receptor functions by direct protein-protein interactions with the dopamine D1 receptor. Cell 111:219-30.

Levin J, Kurz A, Arzberger T, Giese A, Höglinger GU (2016) The differential diagnosis and treatment of atypical parkinsonism. Dtsch Arztebl Int 113: 61-69

Lim J, Yue Z (2015) Neuronal aggregates: formation, clearance, and spreading. Dev Cell 32: 491-501

Litvan I, Agid Y, Calne D, Campbell G, Dubois B, Duvoisin RC, Goetz CG, Golbe LI, Grafman J, Growdon JH, Hallett M, Jankovic J, Quinn NP, Tolosa E, Zee DS (1996) Clinical research criteria for the diagnosis of progressive supranuclear palsy (SteeleRichardson-Olszewski syndrome): report of the NINDS-SPSP international workshop. Neurology 47: 1-9

Litvan I, Bhatia KP, Burn DJ, Goetz CG, Lang AE, McKeith I, Quinn N, Sethi KD, Shults C, Wenning GK (2003) Movement Disorders Society Scientific Issues Committee report: SIC Task Force appraisal of clinical diagnostic criteria for Parkinsonian disorders. Mov Disord 18: 467-486 
Low PA, Reich SG, Jankovic J, Shults CW, Stern MB, Novak P, Tanner CM, Gilman S, Marshall FJ, Wooten F, Racette B, Chelimsky T, Singer W, Sletten DM, Sandroni P, Mandrekar J (2015) Natural history of multiple system atrophy in the USA: a prospective cohort study. Lancet Neurol 14: 710-719

Marsden CD (1994) Problems with long-term levodopa therapy for Parkinson's disease. Clin Neuropharmacol. 17 Suppl 2: S32-44

Meissner WG, Laurencin C, Tranchant C, Witjas T, Viallet F, Guehl D, Damier P, Houeto JL, Tison F, Eusebio A, Vital A, Streichenberger N, Lannes B, Maues de Paula A, Thobois $S$ (2016) Outcome of deep brain stimulation in slowly progressive multiple system atrophy: A clinico-pathological series and review of the literature. Parkinsonism Relat Disord 24: 69-75

Mouradian MM, Juncos JL, Fabbrini G, Schlegel J, Bartko JJ, Chase TN (1988) Motor fluctuations in Parkinson's disease: central pathophysiological mechanisms, Part II. Ann Neurol 24: 372-378

Mudher A, Colin M, Dujardin S, Medina M, Dewachter I, Alavi Naini SM, Mandelkow EM, Mandelkow E, Buee L, Goedert M, Brion JP (2017) What is the evidence that tau pathology spreads through prion-like propagation? Acta Neuropathol Commun 5: 99

Narasimhan S, Guo JL, Changolkar L, Stieber A, McBride JD, Silva LV, He Z, Zhang B, Gathagan RJ, Trojanowski JQ, Lee VMY (2017) Pathological tau strains from human brains recapitulate the diversity of tauopathies in nontransgenic mouse brain. $\mathrm{J}$ Neurosci 37: 11406-11423

Nieforth KA, Golbe LI (1993) Retrospective study of drug response in 87 patients with progressive supranuclear palsy. Clin Neuropharmacol 16: 338-346

Nutt JG (2007) Continuous dopaminergic stimulation: is it the answer to the motor complications of levodopa? Mov Disord 22: 1-9

Olanow CW (2010) Initiating levodopa/carbidopa therapy with and without entacapone in early Parkinson disease: the STRIDE-PD study. Ann Neurol 68: 18-27

Olanow CW, Kieburtz K, Rascol O, Poewe W, Schapira AH, Emre M, Nissinen H, Leinonen M, Stocchi F; Stalevo Reduction in Dyskinesia Evaluation in Parkinson's Disease (STRIDE-PD) Investigators (2013) Factors predictive of the development of Levodopa-induced dyskinesia and wearing-off in Parkinson's disease. Mov Disord 28: 1064-1071

Olanow CW, Kieburtz K, Odin P, Espay AJ, Standaert DG, Fernandez HH, Vanagunas A, Othman AA, Widnell KL, Robieson WZ, Pritchett Y, Chatamra K, Benesh J, Lenz 
RA, Antonini A; LCIG Horizon Study Group (2014) Continuous intrajejunal infusion of levodopa-carbidopa intestinal gel for patients with advanced Parkinson's disease: a randomised, controlled, double-blind, double-dummy study. Lancet Neurol 13: 141149

O'Sullivan SS, Massey LA, Williams DR, Silveira-Moriyama L, Kempster PA, Holton JL, Revesz T, Lees AJ (2008) Clinical outcomes of progressive supranuclear palsy and multiple system atrophy. Brain 131(Pt 5): 1362-1372

Papa SM, Chase TN (1996) Levodopa-induced dyskinesias improved by a glutamate antagonist in Parkinsonian monkeys. Ann Neurol 39: 574-578

Politis M, Wu K, Loane C, Brooks DJ, Kiferle L, Turkheimer FE, Bain P, Molloy S, Piccini P (2014) Serotonergic mechanisms responsible for levodopa-induced dyskinesias in Parkinson's disease patients. J Clin Invest 124: 1340-1349

Rascol O, Fabre N (2001) Dyskinesia: L-dopa-induced and tardive dyskinesia. Clin Neuropharmacol 24: 313-323

Respondek G, Hoglinger GU (2016) The phenotypic spectrum of progressive supranuclear palsy. Parkinsonism Relat Disord 22 Suppl 1: S34-S36

Respondek G, Levin J, Höglinger GU (2018) Progressive supranuclear palsy and multiple system atrophy: clinicopathological concepts and therapeutic challenges.

Curr Opin Neurol 31: 448-454

Rietdijk CD, Perez-Pardo P, Garssen J, van Wezel RJ, Kraneveld AD (2017)

Exploring Braak's hypothesis of Parkinson's disease. Front Neurol 8: 37

Sachdev PS, Brüne M (2000) Animal models of acute drug-induced akathisia - a review.Neurosci Biobehav Rev 24: 269-277

Sanci V, Houle S, DaSilva JN (2002) No change in dopamine D1 receptor in vivo binding in rats after sub-chronic haloperidol treatment. Can J Physiol Pharmacol 80: 36-41

Sawa A, Snyder SH (2002) Schizophrenia: diverse approaches to a complex disease. Science 296: 692-695

Sidhu A, Niznik HB (2000) Coupling of dopamine receptor subtypes to multiple and diverse G proteins. Int J Dev Neurosci 18: 669-677

Stocchi F, Rascol O, Kieburtz K, Poewe W, Jankovic J, Tolosa E, Barone P, Lang AE, Olanow CW (2010) Initiating levodopa/carbidopa therapy with and without entacapone in early Parkinson disease: the STRIDE-PD study. Ann Neurol 68: 18-27 
Suchowersky O, Gronseth G, Perlmutter J, Reich S, Zesiewicz T, Weiner WJ (2006) Practice Parameter: neuroprotective strategies and alternative therapies for Parkinson disease (an evidence-based review): report of the Quality Standards Subcommittee of the American Academy of Neurology. Neurology 66: 976-982

Swann NC, de Hemptinne C, Miocinovic S, Qasim S, Wang SS, Ziman N, Ostrem JL, San Luciano M, Galifianakis NB, Starr PA (2016) Gamma oscillations in the hyperkinetic state detected with chronic human brain recordings in Parkinson's disease. J Neurosci 36: 6445-6458

Trojanowski JQ, Revesz T; Neuropathology Working Group on MSA (2007) Proposed neuropathological criteria for the post mortem diagnosis of multiple system atrophy.

Neuropathol Appl Neurobiol 33: 615-620

Vasta R, Nicoletti A, Mostile G, Dibilio V, Sciacca G, Contrafatto D, Cicero CE, Raciti L, Luca A, Zappia M (2017) Side effects induced by the acute levodopa challenge in Parkinson's Disease and atypical parkinsonisms. PLoS One 12: e0172145

Verhagen Metman L, Del Dotto P, van den Munckhof P, Fang J, Mouradian MM, Chase TN (1998) Amantadine as treatment for dyskinesias and motor fluctuations in Parkinson's disease. Neurology 50: 1323-1326

Vitek JL, Giroux M (2000) Physiology of hypokinetic and hyperkinetic movement disorders: model for dyskinesia. Ann Neurol 47(4 Suppl 1): S131-140

Wenning GK, Geser F, Krismer F, Seppi K, Duerr S, Boesch S, Köllensperger M, Goebel G, Pfeiffer KP, Barone P, Pellecchia MT, Quinn NP, Koukouni V, Fowler CJ, Schrag A, Mathias CJ, Giladi N, Gurevich T, Dupont E, Ostergaard K, Nilsson CF, Widner H, Oertel W, Eggert KM, Albanese A, del Sorbo F, Tolosa E, Cardozo A, Deuschl G, Hellriegel H, Klockgether T, Dodel R, Sampaio C, Coelho M, Djaldetti R, Melamed E, Gasser T, Kamm C, Meco G, Colosimo C, Rascol O, Meissner WG, Tison F, Poewe W; European Multiple System Atrophy Study Group (2013) The natural history of multiple system atrophy: a prospective European cohort study. Lancet Neurol 12: $264-274$

Wenning G, Trojanowski JQ, Kaufmann H, Wisniewski T, Rocca WA, Low PA (2018) Is multiple system atrophy an infectious disease? Ann Neurol 83: 10-12

Williams DR, de Silva R, Paviour DC, Pittman A, Watt HC, Kilford L, Holton JL, Revesz T, Lees AJ (2005) Characteristics of two distinct clinical phenotypes in pathologically proven progressive supranuclear palsy: Richardson's syndrome and PSPparkinsonism. Brain 128: 1247-1258 
Williams DR, Litvan I (2013) Parkinsonian syndromes. Continuum (Minneap Minn) 19: 1189-1212

Zhang X, Chou J, Liang J, Xiao C, Zhao Y, Sarva H, Henchcliffe C, Wang F (2019) Data-driven subtyping of Parkinson's disease using longitudinal clinical records: a cohort study. Sci Rep 9: 797 